\title{
Fish movement from nursery bays to coral reefs: a matter of size?
}

\author{
Chantal M. Huijbers • Ivan Nagelkerken • \\ Craig A. Layman
}

Received: 3 July 2014/Revised: 29 November 2014/Accepted: 23 December 2014/Published online: 3 February 2015

(C) The Author(s) 2015. This article is published with open access at Springerlink.com

\begin{abstract}
Movement of fish across habitat boundaries provides an important link between marine ecosystems such as mangroves, seagrass beds, and coral reefs, yet direct evidence of ontogenetic movements across these systems is scarce. We used acoustic telemetry to investigate movement patterns between bay nursery habitats and adult reef habitats by a common Caribbean fish (Lutjanus apodus). We hypothesized that juvenile fish residing in their nurseries increase their home range as they grow and eventually include coral reefs in their activity range before their permanent migration to this adult habitat. Tagged fish were detected by underwater receivers for a period up to 12 months and a clear diel pattern was visible with most detections occurring during
\end{abstract}

Guest editor: Koen Martens / Emerging Trends in Aquatic Ecology

Electronic supplementary material The online version of this article (doi:10.1007/s10750-014-2162-4) contains supplementary material, which is available to authorized users.

C. M. Huijbers

Australian Rivers Institute - Coasts and Estuaries, and School of Environment, Griffith University, Gold Coast, QLD 4222, Australia

C. M. Huijbers · I. Nagelkerken

Department of Animal Ecology and Ecophysiology, Institute for Water and Wetland Research, Radboud University Nijmegen, P.O. Box 9010, 6500 GL Nijmegen, The Netherlands nighttime. Bay-to-reef movements were undertaken by fish that were larger than fish that were only detected in the bay. Stable isotope values of fin tissue from fish that showed reef-ward movements were similar to those of fish remaining in the bay, indicating that these movements were likely exploratory behavior as opposed to repeated feeding excursions. Understanding cross-habitat ontogenetic movements is essential for identification of ecologically relevant spatial scales for management of coastal fish populations.

Keywords Acoustic telemetry · Connectivity · Food web - Nursery habitat - Ontogenetic movement .

Mangrove $\cdot$ Stable isotopes

\section{Introduction}

Connectivity among tropical coastal habitats affects the diversity and productivity that characterize these ecosystems (Nagelkerken et al., 2015). The underlying

\footnotetext{
I. Nagelkerken $(\bowtie)$

Southern Seas Ecology Laboratories, School of Biological Sciences and The Environment Institute, The University of Adelaide, DX 650 418, Adelaide, SA 5005, Australia e-mail: ivan.nagelkerken@adelaide.edu.au

C. A. Layman

Department of Applied Ecology, North Carolina State University, 127 David Clark Labs, Raleigh,

NC 27695-7617, USA
} 
mechanisms that cause fish to move act across multiple spatial and temporal scales. They include both short-term reasons, like daily movements between foraging and resting areas, as well as longer term movements associated with spawning migrations or ontogenetic habitat shifts (Dahlgren \& Eggleston, 2000; Dorenbosch et al., 2004; Krumme, 2009). Knowledge of the spatial scale and patterns of fish movement is important for conservation and management initiatives, including the design of marine protected areas (Beger et al., 2010; Grüss et al., 2011), yet empirical data that quantify ontogenetic fish movements are still scarce.

Many tropical marine fish species have multiple life stages, including a pelagic larval phase and a benthic juvenile and adult phase. During the benthic phase, all life stages can use the same habitat, or juveniles can use separate habitats and migrate to the adult habitat at a later stage (Beck et al., 2001; Adams et al., 2006). For example, back-reef habitats such as seagrass beds and mangrove forests are known to support high densities of juvenile fish, which are assumed to move to the coral reef once they mature (Nagelkerken, 2009). Movement patterns across these habitats have been shown indirectly by underwater visual observations (e.g. Nagelkerken et al., 2000a; Mumby et al., 2004; Tupper, 2007) or changes in isotope signatures of fish tissue or otoliths (e.g. Verweij et al., 2008; Kimirei et al., 2013a, b; Huijbers et al., 2013). However, these methods provide information at the species level without any details on individual behavior, and they are inappropriate to establish if habitat shifts occur abruptly or as a stepwise process with fish migrating slowly from inshore habitats toward reef habitats over time.

Direct evidence of fish movement can be obtained through the use of artificial tags (Gillanders, 2009; Hazen et al., 2012). These vary from relatively simple and inexpensive tags that can be attached to the body of an animal for visual identification, to more advanced internal tags that can be passively or actively tracked. For example, external bead tags can reveal daily movement patterns among back-reef habitats, but such tags last only for a few weeks (Beets et al., 2003; Verweij et al., 2007). Internal tags such as coded wire tags are more useful for long-term studies (Bouwmeester, 2005; Verweij \& Nagelkerken, 2007). However, fish need to be killed to read the individual code on the tag, and this method therefore provides only information about the start (tag) and end (recatch) location without any further information about the specific movement patterns of the fish during the tag period. Acoustic telemetry is increasingly being used to examine continuous fish movements, providing a method for continuously monitoring fish migrations over longer periods in their natural environment (e.g. Luo et al., 2009; Meyer et al., 2010; Farmer \& Ault, 2011; Alos et al., 2011).

In this study, acoustic telemetry was used to investigate individual differences in bay-to-reef movement patterns in schoolmaster snapper Lutjanus apo$d u s$. We hypothesized that fish will increase their home range as they grow and eventually include the coral reef area in their activity range before their permanent migration to the adult habitat. These changes in movement behavior are likely driven by a combination of lowered predation risk, higher food availability on the reef, and the location of reproduction (Grol et al., 2011; Kimirei et al., 2013a, b). We therefore tested if movement patterns and core area of activity differ among (a) fish of different body sizes, and (b) fish from various nursery sites located at different distances from the coral reef. Additionally, stable carbon isotope signatures of fin tissue were analyzed to test if differences in areas of activity and movement patterns are associated with diet of the individual fish.

\section{Materials and methods}

Study area and species

This study was conducted on the island of Curaçao in the Southern Caribbean Sea $\left(12^{\circ} 07^{\prime} \mathrm{N}, 68^{\circ} 55^{\prime} \mathrm{W}\right)$. Movement patterns of schoolmaster snappers Lutjanus apodus were studied in the channel of Spanish Water Bay (Fig. 1), which connects the central part of the bay with the adjacent coral reef. This channel is relatively long $(1.1 \mathrm{~km})$ and deep $(11-18 \mathrm{~m})$. Substrates in shallow parts of the channel support turtle grass Thalassia testudinum, with some isolated stands of red mangrove Rhizophora mangle along shorelines. The average daily tidal range is $30 \mathrm{~cm}$. The shallow (6-m water depth) mouth of the bay is $85 \mathrm{~m}$ wide, and situated at the sheltered southwestern coast of the island. The fringing coral reef stretches along the entire southwestern coast of Curaçao. From the shore, the reef terrace gradually slopes to $7-9 \mathrm{~m}$ depth, where 


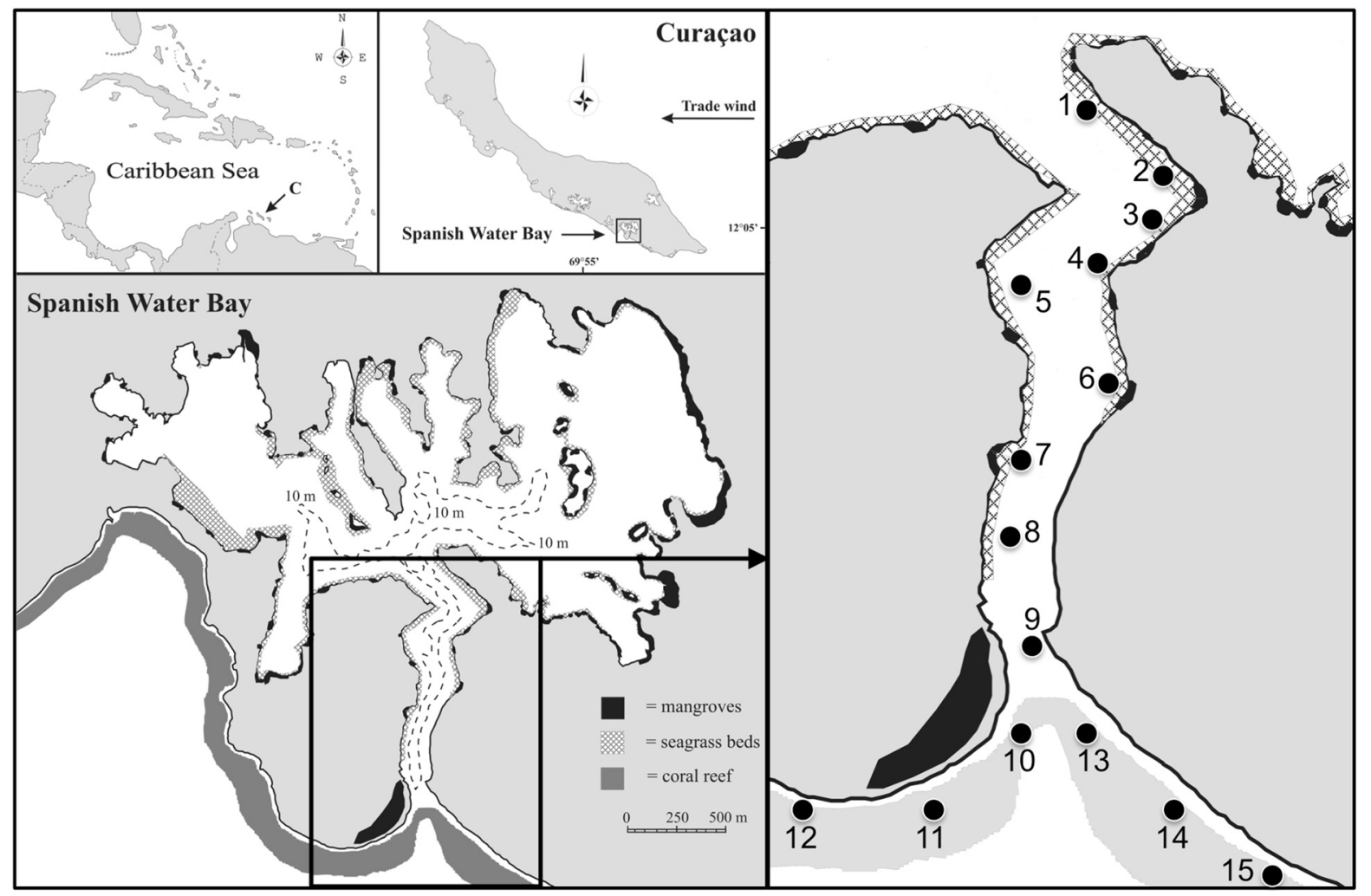

Fig. 1 Overview of the study area. The right panel shows the arrangement of receivers in the channel (1-9) and on the coral reef $(10-15)$

a steep drop-off starts that ends in a sandy plain at 80-90 m.

Schoolmaster snapper is an abundant and commercially important Caribbean fish species (family Lutjanidae). The species is a zoobenthivore, which mainly feeds at night and shelters in structurally complex habitat types during the day (Verweij et al., 2006). Juveniles of this species are highly associated with mangrove habitat, while larger ( $>20 \mathrm{~cm}$ total length) (sub)adults are mainly found on the coral reef (Nagelkerken et al., 2000b; Cocheret de la Morinière et al., 2002; Mateo et al., 2010). Fish reach maturity at approximately $25 \mathrm{~cm}$ (Munro, 1983).

\section{Tagging and tracking}

Schoolmaster snappers were captured with fish traps in the channel overnight, and by hook and line during the day between August and December 2008. Fish were anesthetized in a mixture of fresh seawater and clove oil, and measured for fork length (FL) to the nearest millimeter. Small acoustic transmitters (V7, Vemco;
$18 \mathrm{~mm}$ long) were surgically implanted in the abdominal cavity of the fish through a $1 \mathrm{~cm}$ incision between the pelvic and anal fins. The incision was closed with two stitches using a C-curved needle with attached suture. After the surgery, fish were transferred to a bin with fresh seawater and released after approximately $1 \mathrm{~h}$, during daytime hours. All tagged fish seemed alert and swam away vigorously upon release in the water. A total of 72 fish were tracked with these acoustic tags, of which 49 were pre-programed with 180-300 s delays between individual transmissions ('slow pingers'), and 23 tags with 30-90 s delays ('fast pingers'). Each tag transmits a unique acoustic pulse train, which permits identification of individual fish. The estimated battery life was 420 days for slow pingers and 140 days for fast pingers.

To monitor fish movements, an array of 15 stationary omnidirectional acoustic receivers (VR2, Vemco) was deployed in the channel of Spanish Water Bay and on the adjacent coral reef. Eight receivers were placed in the channel area of the bay, one receiver in the mouth of the bay, and six receivers were 
placed on the coral reef (Fig. 1). Seven of the receivers in the bay were located at 'home sites' (Hammerschlag-Peyer \& Layman, 2010), i.e., where groups of fish sheltered during the day (hereafter referred to as 'home receivers'), and one receiver was placed at an additional site in-between home sites (\#4 in Fig. 1). Each receiver continuously recorded the time and date of each passage of a tagged fish. Data were regularly downloaded from each receiver throughout the study period, which lasted from August 2008 till August 2009. During the first 6 months, data from the receivers were downloaded every month. Upon retrieval from the water in August 2009, three reef receivers were missing, and thus data from these receivers are lacking for the last 6 months of the study. The detection range of receivers depends on the water depth, turbidity, and habitat complexity and might thus have differed among receivers. The detection range was estimated to be smaller $(<50 \mathrm{~m})$ in the shallow areas of the channel than in the deeper water of coral reef $(>100 \mathrm{~m})$ based on results from other studies (Luo et al., 2009; Meyer et al., 2010; Topping \& Szedlmayer, 2011).

In addition to these stationary receivers, a handheld receiver and hydrophone (VR100, Vemco) were used on four separate days (25-26 October and 14-15 December 2008) to detect tagged fish throughout the study area and on the reef, beyond the detection range of the receivers, and in other areas outside the bay not covered by the receivers. This mobile tracking was done from a small boat with the hydrophone towed in the water column halfway between the substrate and the surface. In case of a detection, the individual code of the fish, the coordinates of its position, and the date and time were automatically recorded by the receiver.

\section{Stable isotope analysis}

For each tagged fish, a small sample of the dorsal fin tissue was removed for stable isotope analysis. Stable carbon isotope values in tissue reflect recent (weeks to months) food sources (Hobson, 1999). Stable isotope values of fin clips are similar to those in fish muscle tissue, which is used most often in stable isotope studies, but allows the fish to be released alive and unharmed (Jardine et al., 2011). The fin samples were dried at $60^{\circ} \mathrm{C}$ for $48 \mathrm{~h}$ and then ground to a homogenous powder. Approximately, $0.3 \mathrm{mg}$ of sample was used for the analysis. $\delta^{13} \mathrm{C}$ and $\delta^{15} \mathrm{~N}$ were measured using a Finnigan EA-IRMS (elemental analyzerisotope ratio mass spectrometer) with Dynamic Flash Combustion. Stable isotope ratios are expressed relative to Vienna PDB standard for $\delta^{13} \mathrm{C}$, and atmospheric nitrogen for $\delta^{15} \mathrm{~N}$. Average reproducibility of carbon and nitrogen isotope values was $<0.15 \%$.

\section{Data analysis}

Tagged fish ranged in size between 10.8 and $27.1 \mathrm{~cm}$ FL $($ mean $=16.9 \mathrm{~cm})$, and thus presumably included both juvenile and mature fish. There were significant differences in body size between fish equipped with fast (mean $\mathrm{FL} \pm \mathrm{SD}=14.8 \pm 2.4 \mathrm{~cm}$ ) and slow $(17.9 \pm 4.3 \mathrm{~cm})$ pingers (independent $t$ test, $P<0.001)$. Therefore, the effect of body size on detection variables was analyzed for these two groups separately.

Linear regression was used to test for the effect of fish size (FL) on the number of receivers at which a fish was detected, the detection span in days (day tagged-last day detected), number of days detected, total number of detections, and maximum distance recorded away from the home receiver, respectively. For fish that were detected by multiple receivers, the maximum recorded distance was estimated using the shortest linear receiver-to-receiver distance between the home receiver and the receiver farthest away from the home area. For fish detected at only a single receiver, this distance was set at $50 \mathrm{~m}$ which is approximately the maximum detection diameter in the shallow bay. This maximum distance recorded was used as a measure of the core area of activity for each individual fish. The influence of body size on the diel activity pattern (percentage day and night detections) of fish was tested using logistic regression. Cluster analysis was used to calculate similarity in the carbon and nitrogen stable isotope values among individual schoolmasters. Additionally, we used a multivariate analysis of variance (MANOVA) to detect differences in stable carbon and nitrogen isotope values of tissue collected from fish from different home sites.

\section{Results}

Detection frequency

In total, 341,342 tag detections were obtained over the course of 12 months, of which only 76 signals were 
detected outside the bay area (either in the mouth of the bay or on the coral reef). Two fish were never detected after release, and seven fish were detected $<12$ times. These nine fish were excluded from the dataset, leaving 63 fish for the analysis.

Fish with fast pingers $(n=21)$ were detected 11,455 times on average (range 16-60,372) across an average period of 109 days (range 3-155). Twelve fish with fast pingers were detected throughout the period of estimated battery life (146-155 days). Fish with slow pingers $(n=42)$ were detected 2,458 times on average (range 12-22,305) across an average period of 174 days (range 3-363). Three fish with slow pingers were detected throughout the study period (360363 days). The ratio of total days detected to total days monitored ranged among individuals from 0.03 to 1.0 (average \pm sd: $0.7 \pm 0.3$ ), but did not differ between fish with fast or slow pingers (independent $t$ test, $P=0.288$ ). Although individual fish were detected for a period up to 363 days, there was substantial variation in the frequency of detections over time. While some fish were detected on a daily basis throughout the period, others were detected frequently only in the first weeks after tagging and sporadically thereafter.

\section{Effect of body size}

For fish with fast pingers, the number of receivers visited, the number of detections, and the maximum distance recorded away from the home receiver were significantly related to fish body size. The detection span and the number of days during which a fish was detected were not affected by body size (Table 1). There was no relationship between fish size and any of the above dependent variables for fish with slow pingers.

\section{Core area of activity}

Nineteen schoolmasters were detected at only one receiver (Fig. 2), which was always the receiver where they had been tagged. Sixteen fish were detected at two receivers, with the majority of these detections (87\%) at the home receiver. For 13 of these 16 fish, the second receiver was the nearest receiver from their home site within a maximum distance of $230 \mathrm{~m}$. For fish that were detected at 3-7 receivers, less than $14 \%$ of the detections were picked up by receivers other than the home receiver. One fish was detected by 9 different receivers, and in contrast to other fish, the majority of these detections $(57 \%)$ were not at the home receiver. Most fish $(n=55$ out of 63) were detected at receivers within a distance of $500 \mathrm{~m}$ from their home receiver (Fig. 3).

\section{Day/night patterns}

There was a clear temporal pattern in the percentage of detections, regardless of the use of fast or slow pingers (Fig. 4). Between 12:00 and 19:00 h, the percentage of detections per hour was almost half of that recorded during the night. The highest percentage for slow pingers was observed after sunrise (07:00-09:00 h). For fish with fast pingers, detections were high during the night and from 07:00 to 09:00 h. Fish equipped with each of the two types of pingers showed a short, but conspicuous decrease in detections around 06:00 h. The proportion of night detections (18:30-06:30 h) was positively correlated with body size for fish with fast pingers (logistic regression, $P=0.012$ ), but not for fish with slow pingers $(P>0.05)$.

\section{Bay-to-reef movements}

Movement between the mangrove and seagrass areas in the channel of the bay and the adjacent coral reef was detected for seven individuals (Table 2; Fig. 5). These seven fish were significantly larger (independent $t$ test, $P=0.039$ ) in size (mean $\mathrm{FL}=19.8 \pm$ $3.9 \mathrm{~cm}$ ) than fish for which no movement toward the reef was detected $(16.5 \pm 4.0 \mathrm{~cm}, n=56)$. Six of the seven fish that showed reef-ward movement were detected at the receiver in the mouth of the bay (\#9), which connects the bay to the coral reef. It is likely that these fish moved between the bay habitats and the coral reef; however, only one of these fish was also detected at a reef receiver. The seventh fish was not detected in the mouth of the bay, but only at one of the reef receivers (\#12).

Three fish were detected at their home receivers before and after their detection in the mouth of the bay. One of these fish (\#51073, Table 2) visited the reef three times with approximately 1 month in-between each visit. Two fish were never detected in the channel after having passed the receiver in the mouth of the bay, and thus might have moved permanently to the reef despite the lack of detections on reef receivers. 
Table 1 Effect of body size on detection variables for schoolmaster snappers tagged with fast

(transmissions with 30-90 s delays) or slow (180-300 s delays) pingers, based on linear regression analyses

Significant $P$ values are shown in bold

Fig. 2 Percentage of detections at the home receiver versus other receivers. Total number of fish per category is given above the bars

\begin{tabular}{lllrl}
\hline & Fast/Slow & $R^{2}$ & Slope & $P$ value \\
\hline Number of receivers visited & Fast & 0.28 & 0.34 & $\mathbf{0 . 0 1 3}$ \\
& Slow & 0.04 & 0.08 & 0.197 \\
Detection span in days & Fast & 0.19 & 10.66 & 0.051 \\
& Slow & 0.00 & -0.66 & 0.892 \\
Days detected & Fast & 0.12 & 8.44 & 0.132 \\
Number of detections & Slow & 0.02 & 3.86 & 0.337 \\
& Fast & 0.24 & 3756.70 & $\mathbf{0 . 0 2 3}$ \\
Maximum distance recorded & Slow & 0.04 & 212.46 & 0.221 \\
away from home receiver & Fast & 0.26 & 27.78 & $\mathbf{0 . 0 1 9}$ \\
& Slow & 0.01 & 6.31 & 0.666 \\
\hline
\end{tabular}

$\square$ other receiver(s) $\square$ home receiver
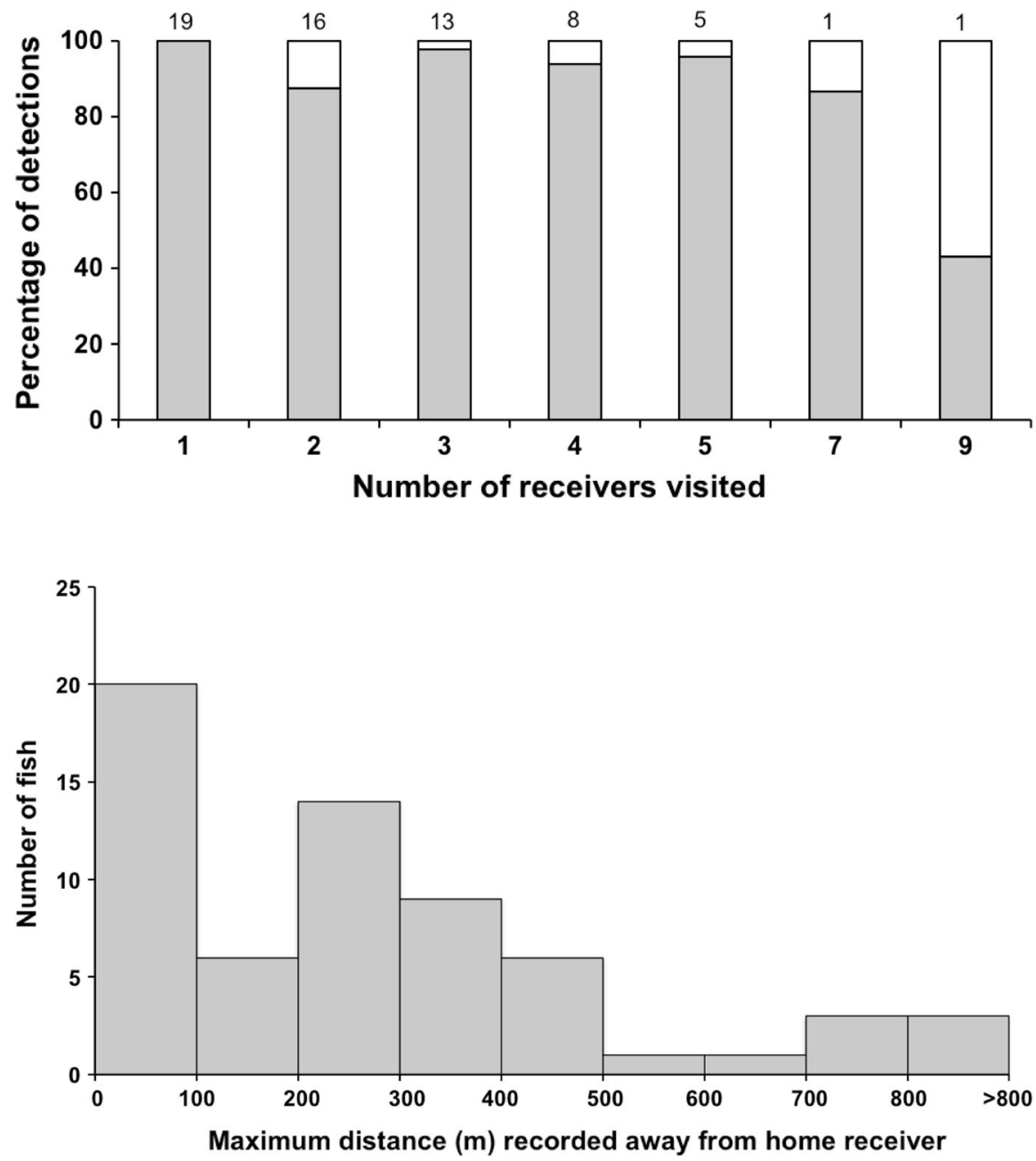

Fig. 3 Frequency

histogram of the estimated maximum distance that fish were detected away from their home receiver 


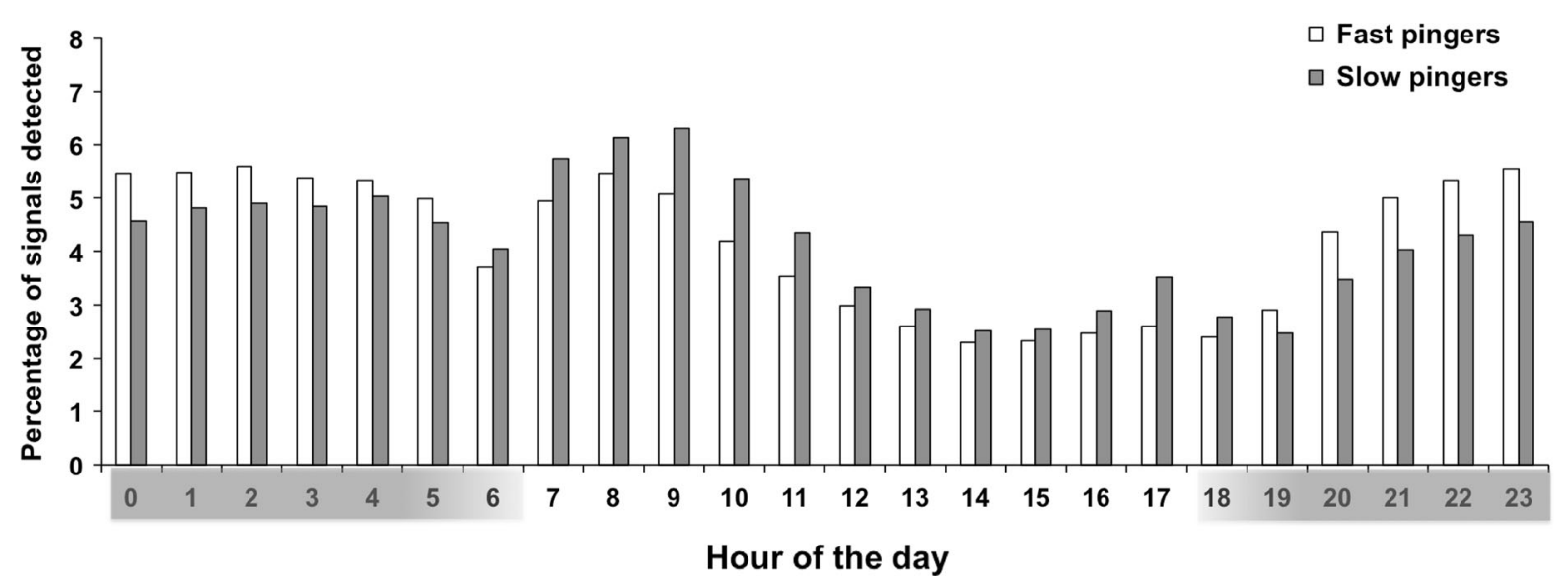

Fig. 4 Hourly distribution of signals from fast and slow pingers detected by receivers in the bay. Nighttime hours are shaded in gray below the $x$-axis

The two fish that were detected by reef receivers were detected by the receivers placed farthest away, approximately $1 \mathrm{~km}$ from the mouth of the bay (\#12 and 14) (Table 2; Fig. 5). Fish 50593 was detected for $38 \mathrm{~h}$ after release in the vicinity of its home site. From there, the fish showed nocturnal movement through the bay toward the reef. The last detection of this fish was on the farthest reef receiver, 2 days after it had been tagged. The second fish that moved to the coral reef (51070) had been tagged in the channel area of the bay, where it was detected every hour for $24 \mathrm{~h}$ after release. It went undetected for 10 days, before it was detected at reef receiver 14 . Thereafter, it was detected on 7 different days between 27 December 2008 and 6 August 2009 at the same reef receiver. These detections always occurred during daytime between 8:53 and 17:57 h.

Movement between the bay and the coral reef occurred mainly during nighttime, as 5 out of 6 fish passed the receiver in the mouth of the bay between 00:00 and 06:00 h. The time between the last detection in the bay and the first detection in the mouth of the bay was relatively long (range 1:52-3:59 h) considering the inter-receiver distances (only a few hundred meters) and potential swim range and speed of this species.

\section{Stable isotope values}

There were no significant differences among fish from different home sites for either $\delta^{13} \mathrm{C}$ or $\delta^{15} \mathrm{~N}$
(MANOVA, $P=0.195$ and 0.103 for nitrogen and carbon stable isotopes, respectively). Cluster analysis based on both carbon and nitrogen stable isotope values of all tagged schoolmasters showed a separation in two main clusters although similarity between clusters was high (90\%; see Appendix). This separation could not be explained by differences in home site, the number of receivers visited, or the maximum distance a fish was detected away from the home receiver, but was significantly related to fish size (independent $t$ test, $P=0.007$ ). Although $\delta^{15} \mathrm{~N}$ did not differ between clusters, $\delta^{13} \mathrm{C}$ was more depleted in the cluster with smaller fish (mean $\delta^{13} \mathrm{C}$ value $=$ $-16.7 \%$ for mean FL of $15.3 \mathrm{~cm}$ ), compared to the cluster with larger fish $\left(\delta^{13} \mathrm{C}\right.$ value $=-12.2 \%$ for $\mathrm{FL}$ of $18.0 \mathrm{~cm}$ ). Fish that were detected at the receiver in the mouth of the bay or at a reef receiver did not have different stable isotope values than those fish that were only detected in the bay (MANOVA, $P=0.201$ and 0.966 for nitrogen and carbon stable isotopes, respectively).

\section{Discussion}

Movements of fish across habitat boundaries can serve as important linkages between ecosystems (Pittman \& McAlpine, 2003). However, it is often challenging to study movement patterns, especially for habitat shifts that occur only occasionally, such as ontogenetic habitat shifts. Acoustic telemetry enabled us to detect 


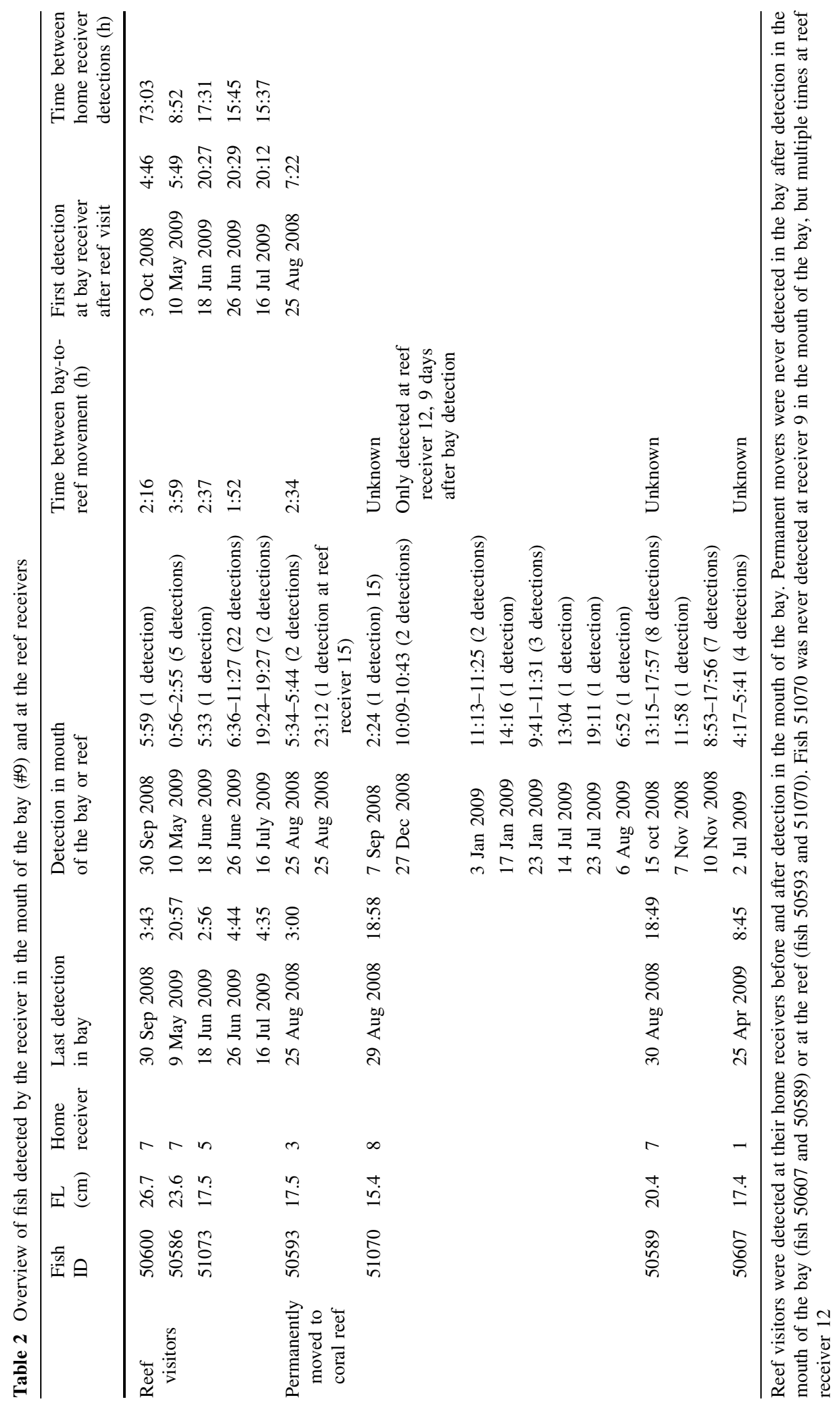


Reef visitors

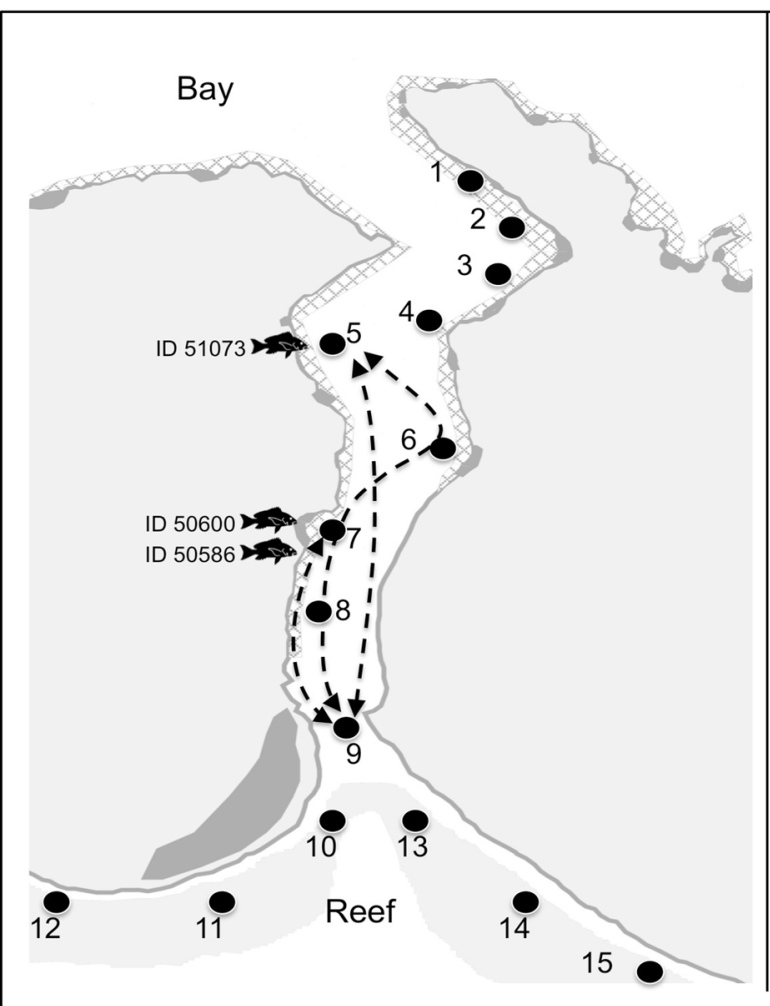

Fig. 5 Overview of reef-ward movements of seven individual fish. The left panel shows patterns of three 'reef visitors', i.e., fish that were detected in the bay before and after detection on the reef or in the mouth of the bay. Two fish were only detected at their home receiver and receiver \#9 (ID 51073 and 50586), while the third fish was detected at several receivers in the channel and the mouth of the bay (ID 50600). The right panel shows patterns of four fish that were never detected in the bay

individual differences in fish habitat use and movement patterns, which could partly be explained by differences in body size. Larger fish were detected at more receivers, had larger activity home ranges, and were more active at night than smaller fish. Bay-toreef movement patterns were detected for fish that were significantly larger than fish that were only detected in the bay. Movements of fish that did not return to the bay occurred rather abrupt, even for fish with home sites located deeper in the bay.

Tagged schoolmaster snappers in this study used a restricted number of home sites. Some fish were detected at receivers close to their home receiver, but they did not use the entire channel area despite the availability of continuous coastline with shelter and
Permanently moved to reef

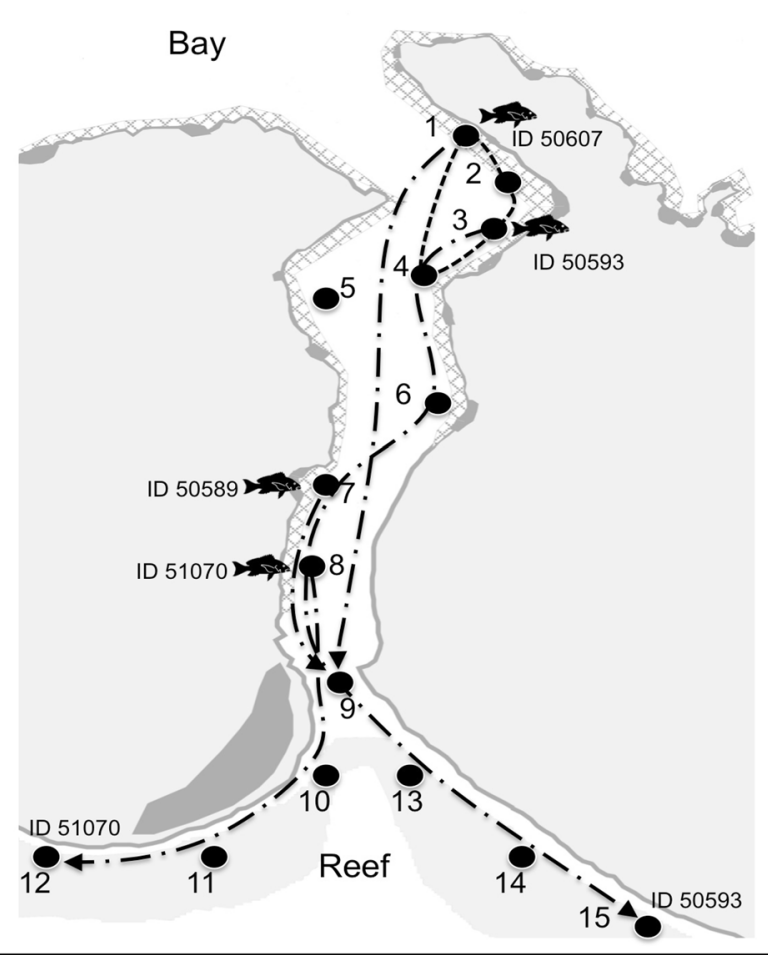

after movement to the reef, and might thus have moved permanently to the adult habitat. Two of these fish (ID 50607 and 50589) were only detected in the mouth of the bay (receiver \#9), and not on the reef receivers, one fish was not detected by receiver $\# 9$, but several times by reef receiver 12 (ID 51070), and one fish travelled through the channel where it was detected by several receivers before moving to the reef (ID 50593). See Table 2 for detailed information on detections for each fish ID

feeding habitat. Previous studies have shown that both habitat specialists and ontogenetic habitat shifters can exhibit strong site fidelity during a specific life stage (Zeller, 1997; Marnane, 2000; Lindholm et al., 2006). Within these restricted daily home ranges, differences have been observed between the extents of day and night spaces due to differences in activity pattern (i.e., resting vs. foraging) (Luo et al., 2009; Meyer et al., 2010; Farmer \& Ault, 2011). The larger number of detections during the nighttime in our study might indicate more activity during this period, yet we did not observe an increase in activity space (i.e., the number of receivers on which a fish is detected) during the night. Similar to Verweij et al. (2007), who found a daytime activity radius of 6-325 m over 17-90 days 
for schoolmaster snappers in the same area, our results show schoolmasters frequent particular areas of the bay for long periods of time.

A clear pattern in diel detection frequency was observed, with fewer detections during the afternoon compared to the morning and nighttime. The increase in detections during the night, in particular for larger fish, is indicative of nocturnal feeding behavior. These results correspond with previous studies recording diel movement behavior of schoolmasters (Hitt et al., 2011). Fish equipped with both types of pingers showed a considerable decrease in detections at sunrise around 06:00 h. This coincides with the crepuscular period in which predation is assumed to be most intense (Helfman, 1986). Temporal variation in predation risk is an important factor driving animal behavior (Lima \& Bednekoff, 1999) and might thus have caused the decrease in movement detections of schoolmasters during sunrise.

Although bay-to-reef movement was mainly observed during the night, this behavior did not seem to be principally driven by feeding migrations, as the stable isotope values in fin tissue of fish that showed these movements were similar to fish that resided in the bay. Fish were thus predominantly feeding in the bay, but could be divided in two different clusters based on differences in $\delta^{13} \mathrm{C}$ values of their fin tissue, which was related to body size. Carbon isotope values of potential food items in the mangroves generally have values lower than $-16 \%$ (Cocheret de la Morinière et al., 2003; Nagelkerken \& van der Velde, 2004), which corresponds with the more depleted $(-16.7 \%)$ carbon isotope values of small fish (mean FL: $15.3 \mathrm{~cm}$ ) in our study. Values of $\delta^{13} \mathrm{C}$ in fin tissue of larger fish $(-12.2 \%$, mean FL: $18.0 \mathrm{~cm})$ resembled the more enriched values of a diet composed of Tanaidacea, shrimps, and crabs found in seagrass beds (Cocheret de la Morinière et al., 2003). Combined with our findings that larger fish had a larger core area of activity and a significant increase in detections during the night, this indicates that these fish forage in seagrass beds for food at night, while smaller fish shelter and feed primarily in the mangroves (Nagelkerken \& van der Velde, 2004).

Movements from the bay toward the reef were observed for only a few fish. These occurred mainly during the night, corresponding to observed bay-toocean movements of gray snapper in the Florida Keys, where migrations of three fish to and from the reef all occurred at night (Luo et al., 2009). For fish that moved toward the reef and then back to their home area, there was a delay in return of a daytime period suggesting that fish sheltered elsewhere during daytime after having moved past the bay mouth. In the same channel, Verweij et al. (2007) externally tagged 59 schoolmaster snappers of similar size range $(13.2-21 \mathrm{~cm})$, and surveyed the area for 99 days. Over this time frame, they detected four fish on the reef (7\% of all fish tagged) with 1-13 reef detections for each fish, which is comparable to our results $(11 \%$ of tagged fish detected on the reef, with 1-22 detections for each fish). In both their and our study, movement to the reef was only observed for individuals $>15.4 \mathrm{~cm}$. Movement to new territory might be risky and therefore fish might initiate such movement only at larger size classes when they exceed the gape size of potential predators. Alternatively, there is also the possibility that these shifts to coral habitat might be driven by the onset of reproductive maturation (Grol et al., 2014).

Several explanations can be proposed for the low number of fish detected on the coral reef: either fish are residing in their nurseries for much longer periods than previously thought (Gillanders et al., 2003), fast movements by reef-visiting fish were not detected due to the relatively long delays between pinger transmission, or fish on reefs were not detected due to the relatively poor coverage of the receiver array. This shows that while improvements in technology have already advanced our understanding of particular fish behavior (Hazen et al., 2012), there are still limitations to quantifying ontogenetic movement patterns over longer time scales, which are often caused by a tradeoff between tag size and battery life. We tagged fish with acoustic tags with two different delay intervals, fast pingers with a delay of 30-90 s between transmissions, and slow pingers with a 180-300 s delay. The minimum delays of 30 and $180 \mathrm{~s}$ are still long enough for fish to pass the receiver in the mouth of the bay or on the reef without being detected. Fish that were never detected on the reef did thus not necessarily remain exclusively in the bay. Moreover, fish for which bay-to-reef movement was detected were all equipped with slow pingers, indicating that a faster pinger rate did not lead to a higher chance of detection.

It remains unknown if the decline in number of fish detected throughout the study period is due to premature transmitter failure, mortality of the fish or 
emigration from the study site. Yet, such declines have been reported in previous studies as well (Meyer et al., 2010). The receivers in this study only covered a small area on the reef and in the bay; the reef extends for many kilometers to both the eastern and western sides of the study area, while the channel covers only a small surface area of the larger embayment area. It is possible that fish did not remain within the channel area throughout the study, or were still present but not detected because they were beyond the range of the receiver array. On 4 days, a manual tracker was used to detect fish on the coral reef (up to $2 \mathrm{~km}$ from the mouth of the bay), but this did not result in additional detections. It remains disputable if non-sightings are the result of the large variability in individual fish behavior, or due to technological limitations. It remains a challenge to match technological trade-offs, i.e., pinger rate, battery life, distance between receivers, array size, to the variability in movement patterns and strategies of the species of interest. Nevertheless, acoustic tracking is becoming an increasingly useful tool to capture ecological variability in animal movement patterns and put this in the context of intra- and interspecific variation in migration patterns of marine populations.

In conclusion, our results show that movement from nursery habitats in a sheltered bay to nearshore coral reefs can occur very abrupt. Fish did not simply move at random until a more suitable habitat was found, or relocate or expand their home range in a stepwise process from the bay toward the coral reef. Initiation of reef-ward movement was driven by body size, which can be related to a lower predation risk, the need for larger prey, or the onset of maturation. A better understanding of the spatial scale and patterns of ontogenetic movements is important for better management of these systems and design of marine protected areas.

Acknowledgements This study was financially supported by the Netherlands Organization for Scientific Research (NWO) through a VIDI Grant to IN, as well as U.S. National Science Foundation Grant OCE \#0746164 to CAL. We would like to thank Martijn van der Ende, Ines Schulten, Pauline Lössbroek, Andjin Siegenthaler and Carlos Villegas for their logistic support in the field, and Jelle Eygensteyn (General Instrumentation Department) for the stable isotope analysis.

Open Access This article is distributed under the terms of the Creative Commons Attribution License which permits any use, distribution, and reproduction in any medium, provided the original author(s) and the source are credited.

\section{References}

Adams, A. J., C. P. Dahlgren, G. T. Kellison, M. S. Kendall, C. A. Layman, J. A. Ley, I. Nagelkerken \& J. E. Serafy, 2006. Nursery function of tropical back-reef systems. Marine Ecology Progress Series 318: 287-301.

Alos, J., D. March, M. Palmer, A. Grau \& B. Morales-Nin, 2011. Spatial and temporal patterns in Serranus cabrilla habitat use in the NW Mediterranean revealed by acoustic telemetry. Marine Ecology Progress Series 427: 173-186.

Beck, M. W., K. L. Heck, K. W. Able, D. L. Childers, D. B. Eggleston, B. M. Gillanders, B. Halpern, C. G. Hays, K. Hoshino, T. J. Minello, R. J. Orth, P. F. Sheridan \& M. R. Weinstein, 2001. The identification, conservation, and management of estuarine and marine nurseries for fish and invertebrates. Bioscience 51: 633-641.

Beets, J., L. Muehlstein, K. Haught \& H. Schmitges, 2003. Habitat connectivity in coastal environments: patterns and movements of Caribbean coral reef fishes with emphasis on bluestriped grunt, Haemulon sciurus. Gulf and Caribbean Research 14: 29-42.

Beger, M., H. S. Grantham, R. L. Pressey, K. A. Wilson, E. L. Peterson, D. Dorfman, P. J. Mumby, R. Lourival, D. R. Brumbaugh \& H. P. Possingham, 2010. Conservation planning for connectivity across marine, freshwater, and terrestrial realms. Biological Conservation 143: 565-575.

Bouwmeester, B. L. K., 2005. Ontogenetic migration and growth of French grunt (Teleostei: Haemulon flavolineatum) as determined by coded wire tags. M.S. Thesis, University of Puerto Rico.

Cocheret de la Morinière, E. C., B. J. A. Pollux, I. Nagelkerken \& G. van der Velde, 2002. Post-settlement life cycle migration patterns and habitat preference of coral reef fish that use seagrass and mangrove habitats as nurseries. Estuarine Coastal and Shelf Science 55: 309-321.

Cocheret de la Morinière, E. C., B. J. A. Pollux, I. Nagelkerken, M. A. Hemminga, A. H. L. Huiskes \& G. van der Velde, 2003. Ontogenetic dietary changes of coral reef fishes in the mangrove-seagrass-reef continuum: stable isotopes and gut-content analysis. Marine Ecology Progress Series 246: 279-289.

Dahlgren, C. P. \& D. B. Eggleston, 2000. Ecological processes underlying ontogenetic habitat shifts in a coral reef fish. Ecology 81: 2227-2240.

Dorenbosch, M., M. C. Verweij, I. Nagelkerken, N. Jiddawi \& G. van der Velde, 2004. Homing and daytime tidal movements of juvenile snappers (Lutjanidae) between shallow-water nursery habitats in Zanzibar, western Indian Ocean. Environmental Biology of Fishes 70: 203-209.

Farmer, N. A. \& J. S. Ault, 2011. Grouper and snapper movements and habitat use in Dry Tortugas, Florida. Marine Ecology Progress Series 433: 169-184.

Gillanders, B. M., 2009. Tools for studying biological marine ecosystem - natural and artificial tags. In Nagelkerken, I. (Ed.), Ecological Connectivity Among Tropical Coastal Ecosystems. Springer, Dordrecht: 457-492.

Gillanders, B. M., K. W. Able, J. A. Brown, D. B. Eggleston \& P. F. Sheridan, 2003. Evidence of connectivity between juvenile and adult habitats for mobile marine fauna: an 
important component of nurseries. Marine Ecology Progress Series 247: 281-295.

Grol, M. G. G., I. Nagelkerken, A. L. Rypel \& C. A. Layman, 2011. Simple ecological trade-offs give rise to emergent cross-ecosystem distributions of a coral reef fish. Oecologia 165: 79-88.

Grol, M. G. G., A. L. Rypel \& I. Nagelkerken, 2014. Growth potential and predation risk drive ontogenetic shifts among nursery habitats in a coral reef fish. Marine Ecology Progress Series 502: 229-244.

Grüss, A., D. M. Kaplan, S. Guenette, C. M. Roberts \& L. W. Botsford, 2011. Consequences of adult and juvenile movement for marine protected areas. Biological Conservation 144: 692-702.

Hammerschlag-Peyer, C. M. \& C. A. Layman, 2010. Intrapopulation variation in habitat use by two abundant coastal fish species. Marine Ecology Progress Series 415: 211-220.

Hazen, E. L., S. M. Maxwell, H. Bailey, S. J. Bograd, M. Hamann, P. Gaspar, B. J. Godley \& G. L. Shillinger, 2012. Ontogeny in marine tagging and tracking science: technologies and data gaps. Marine Ecology Progress Series 457: 221.

Helfman, G. S., 1986. Fish behavior by day, night and twilight. In Pitcher, T. J. (Ed.), The Behavior of Teleost Fishes. Croom-Helm, London: 366-387.

Hitt, S. H., S. J. Pittman \& K. A. Brown, 2011. Tracking and mapping sun-synchronous migrations and diel space use patterns of Haemulon sciurus and Lutjanus apodus in the U.S. Virgin Islands. Environmental Biology of Fishes 92: 525-538.

Hobson, K. A., 1999. Tracing origins and migration of wildlife using stable isotopes: a review. Oecologia 120: 314-326.

Huijbers, C. M., I. Nagelkerken, A. O. Debrot \& E. Jongejans, 2013. Geographic coupling of juvenile and adult habitat shapes spatial population dynamics of a coral reef fish. Ecology 94: 1859-1870.

Jardine, T. D., R. J. Hunt, B. J. Pusey \& S. E. Bunn, 2011. A nonlethal sampling method for stable carbon and nitrogen isotope studies of tropical fishes. Marine and Freshwater Research 62: 83-90.

Kimirei, I. A., I. Nagelkerken, M. Trommelen, P. Blankers, N. Van Hoytema, D. Hoeijmakers, C. M. Huijbers, Y. Mgaya \& A. L. Rypel, 2013a. What drives ontogenetic niche shifts of fishes in coral reef ecosystems? Ecosystems 16: 783-796.

Kimirei, I. A., I. Nagelkerken, Y. D. Mgaya \& C. M. Huijbers, 2013b. The mangrove nursery paradigm revisited: otolith stable isotopes support nursery-to-reef movements by Indo-Pacific fishes. PLoS One 8(6): e66320.

Krumme, U., 2009. Diel and tidal movements by fish and decapods linking tropical coastal ecosystems. In Nagelkerken, I. (Ed.), Ecological Connectivity Among Tropical Coastal Ecosystems. Springer, Dordrecht: 271-324.

Lima, S. L. \& P. A. Bednekoff, 1999. Temporal variation in danger drives antipredator behavior: the predation risk allocation hypothesis. American Naturalist 153: 649-659.

Lindholm, J., A. Knight, L. Kaufman \& S. Miller, 2006. Site fidelity and movement of the parrotfishes Scarus coeruleus and Scarus taeniopterus at Conch Reef (northern Florida Keys). Caribbean Journal of Science 42: 138-144.
Luo, J. G., J. E. Serafy, S. Sponaugle, P. B. Teare \& D. Kieckbusch, 2009. Movement of gray snapper Lutjanus griseus among subtropical seagrass, mangrove, and coral reef habitats. Marine Ecology Progress Series 380: 255-269.

Marnane, M. J., 2000. Site fidelity and homing behaviour in coral reef cardinalfishes. Journal of Fish Biology 57: 1590-1600.

Mateo, I., E. G. Durbin, R. S. Appeldoorn, A. J. Adams, F. Juanes, R. Kingsley, P. Swart \& D. Durant, 2010. Role of mangroves as nurseries for French grunt Haemulon flavolineatum and schoolmaster Lutjanus apodus assessed by otolith elemental fingerprints. Marine Ecology Progress Series 402: 197-212.

Meyer, C. G., Y. P. Papastamatiou \& T. B. Clark, 2010. Differential movement patterns and site fidelity among trophic groups of reef fishes in a Hawaiian marine protected area. Marine Biology 157: 1499-1511.

Mumby, P. J., A. J. Edwards, J. E. Arias-Gonzalez, K. C. Lindeman, P. G. Blackwell, A. Gall, M. I. Gorczynska, A. R. Harborne, C. L. Pescod, H. Renken, C. C. C. Wabnitz \& G. Llewellyn, 2004. Mangroves enhance the biomass of coral reef fish communities in the Caribbean. Nature 427: 533-536.

Munro, J. L., 1983. Caribbean coral reef fishery resources. ICLARM, Manila.

Nagelkerken, I., 2009. Evaluation of nursery function of mangroves and seagrass beds for tropical decapods and reef fishes: patterns and underlying mechanisms. In Nagelkerken, I. (ed.), Ecological Connectivity Among Tropical Coastal Ecosystems. Springer, Dordrecht: 357-400.

Nagelkerken, I. \& G. van der Velde, 2004. Relative importance of interlinked mangroves and seagrass beds as feeding habitats for juvenile reef fish on a Caribbean island. Marine Ecology Progress Series 274: 153-159.

Nagelkerken, I., M. Dorenbosch, W. C. E. P. Verberk, E. C. Cocheret de la Morinière \& G. van der Velde, 2000a. Day-night shifts of fishes between shallow-water biotopes of a Caribbean bay, with emphasis on the nocturnal feeding of Haemulidae and Lutjanidae. Marine Ecology Progress Series 194: 55-64.

Nagelkerken, I., M. Dorenbosch, W. C. E. P. Verberk, E. C. Cocheret de la Morinière \& G. van der Velde, 2000b. Importance of shallow-water biotopes of a Caribbean bay for juvenile coral reef fishes: patterns in biotope association, community structure and spatial distribution. Marine Ecology Progress Series 202: 175-192.

Nagelkerken, I., M. Sheaves, R. Baker \& R. M. Connolly, 2015. The seascape nursery: a novel spatial approach to identify and manage nurseries for coastal marine fauna. Fish and Fisheries. doi:10.1111/faf.12057.

Pittman, S. J. \& C. A. McAlpine, 2003. Movements of marine fish and decapod crustaceans: process, theory and application. Advances in Marine Biology, Vol. 44. Academic Press Ltd, London. 205-294.

Topping, D. T. \& S. T. Szedlmayer, 2011. Site fidelity, residence time and movements of red snapper, Lutjanus campechanus estimated with long-term acoustic monitoring. Marine Ecology Progress Series 437: 183-200.

Tupper, M., 2007. Identification of nursery habitats for commercially valuable humphead wrasse Cheilinus undulatus 
and large groupers (Pisces: Serranidae) in Palau. Marine Ecology Progress Series 332: 189-199.

Verweij, M. C. \& I. Nagelkerken, 2007. Short and long-term movement and site fidelity of juvenile Haemulidae in backreef habitats of a Caribbean embayment. Hydrobiologia 592: 257-270.

Verweij, M. C., I. Nagelkerken, D. de Graaff, M. Peeters, E. J. Bakker \& G. van der Velde, 2006. Structure, food and shade attract juvenile coral reef fish to mangrove and seagrass habitats: a field experiment. Marine Ecology Progress Series 306: 257-268.

Verweij, M. C., I. Nagelkerken, K. E. M. Hol, A. H. J. B. van den Beld \& G. van der Velde, 2007. Space use of Lutjanus apodus including movement between a putative nursery and a coral reef. Bulletin of Marine Science 81: 127-138. Verweij, M. C., I. Nagelkerken, I. Hans, S. M. Ruseler \& P. R. D. Mason, 2008. Seagrass nurseries contribute to coral reef fish populations. Limnology and Oceanography 53: 1540-1547.

Zeller, D. C., 1997. Home range and activity patterns of the coral trout Plectropomus leopardus (Serranidae). Marine Ecology Progress Series 154: 65-77. 